\title{
CURRENCY EXCHANGE RATE FORECASTING \\ USING ARTIFICIAL NEURAL NETWORKS \\ BACKPROPAGATION METHOD
}

Difana Meilani, Andalas University - Padang, Indonesia

Ivan Richardo, Andalas University - Padang, Indonesia

\begin{abstract}
Since 1997, the rupiah currency has a tendency to change at any time since the economic crisis that hit Indonesia. One of the currencies of the most widely traded on international exchange market is the U.S. dollar. This paper will forecast the exchange rate by using back propagation neural networks. Variables that affecting currency exchange rates is inflation, gross national product and interest rates. After performing data processing with the help of software VB.net forecasting results and forecasting program will be displayed online using PHP to construct the webpage.
\end{abstract}

Keywords: currency exchange rates forecasting, back propagation, webpage design

\section{INTRODUCTION}

Currency exchange rate is the ratio of a country's currency with another country's currency. Currency is also a macroeconomic variables that very important, because exchange rates can maintain economic stability in a region or country (Muhammad, 2010). One of the currencies of the most widely traded in the international exchange market is the U.S. dollar. In Indonesia, Dollar was used as one indicator in designing the State Budget. Since 1997, the rupiah currency has a tendency to change at any time since the economic crisis that hit Indonesia.

According Defitra, Head of Export Affairs, Cooperatives, Industry and Trade (DISKOPERINDAG) (2011), the exchange rate is never shown in DISKOPERINDAG site, whereas the exchange rate is also influential in the trade between countries. During this exchange rate forecasting is only 
done by the Jakarta Stock Exchange, but not shown on the Jakarta Stock Exchange website, so to be able to know the value of forecasting should come directly to that agency. So do not close the opportunity for DISKOPERINDAG to display the currency rates in their sites, because who visit this site are overseas businesses which of course it needed information about changes in currency exchange rates so that they can determine the best time to do business.

The problems that arise then is how to make predictions based on the exchange rate stochastic processes (probabilistic) with high accuracy. In this case the necessary phenomenon of the dependence on time are realized in a stochastic model (Box, 1994). Artificial neural networks can identify the pattern of the forecasting system data exchange rate of rupiah against the U.S. dollar can be done by the method of approach to training Based on learning skill it has, then the neural network can be trained to study and analyze the patterns of past data and trying to find a formula or function that will link the pattern of past data with the desired output. These network functions describing the dependence of the current data the previous data values. Back propagation is one of the methods of artificial neural networks that can be applied well in the field of forecasting (Siang, 2005).

\section{ARTIFICIAL NEURAL NETWORK}

Artificial neural networks are information processing systems that have characteristics similar to biological neural networks (Siang, 2005). Artificial neural networks are computing systems that are based on modeling of biological system (neurons) via the approach of computational properties of biological (Sekarwati, 2005). Artificial neural networks are computational systems model that can simulate the workings of biological neural networks (Subiyanto, 2002).

\section{BACK PROPAGATION}

Back propagation is an artificial neural network model with multiple layers. As with other artificial neural network model, back propagation trained network to obtain a balance between the network's ability to recognize patterns used during training and networking capabilities to provide the correct response to the input pattern is similar (but not equal) to the patterns used during training. 


\section{BACK PROPAGATION TRAINING}

As with other neural networks, the network feed forward training is done in order to calculate the weights so that at the end of the training will be obtained weights are good. During the training process, the weights iteratively adjusted to minimize error that occur.

Error is calculated based on the mean squared error (MSE). The mean squared error is also used as the basis for calculating the performance of the activation function. Most of the training for feed forward network using a gradient of activation function to determine how to adjust the weights in order to minimize the performance. This gradient is determined by using a technique called back propagation.

Basically, the standard back propagation training algorithm will move the weight with a negative gradient direction. The basic principle of back propagation algorithm is to improve the network weights with the direction that makes the activation function to be falling rapidly

Back propagation training includes three phases as follows.

1. Phase 1, the forward propagation.

Input pattern is calculated forward from the input screen to display output using the specified activation function.
2. Phase 2, the backward propagation.

The difference between the network output with the desired target is the error that occurred. Errors that occur that dipropagasi retreat. Starting from the line that relates directly to units in the output layer.

3. Phase 3 , the weight changes.

Modification of weights to reduce the error that occurred. All three phases are repeated until the termination condition continues to be met.

Training algorithm for backpropagation networks with one hidden layers (with the binary sigmoid activation function) is as follows.

\section{a. Step 0}

Initialize all weights to small random numbers.

\section{b. Step 1}

If the termination condition has not been met, go to step 2-8.

\section{c. Step 2}

For each pair of training data, perform steps 3-8.

d. Step 3 (steps 3-5 is a phase 1)

Each input unit receives the signal and passes it to the hidden units above it.

e. Step 4

Calculate all the outputs in the hidden units $z_{j}(j=1,2, \ldots, p)$ 


$$
\begin{aligned}
& z_{-} \text {net }_{j}=v_{j_{0}}+\sum_{i=1}^{n} x_{i} v_{j i} \\
& z_{j}=f\left(z_{-} \text {net } t_{j}\right)=\frac{1}{1+e^{-z_{-} n e t_{j}}}
\end{aligned}
$$

\section{f. Step 5}

Calculate all network output in the output unit $\mathrm{y}_{\mathrm{k}}(\mathrm{k}=1,2, \ldots, \mathrm{m})$.

$$
\begin{aligned}
& y_{-} n e t_{k}=w_{k 0}+\sum_{j=1}^{p} z_{j} w_{k j} \\
& y_{k}=f\left(y_{-} n e t_{k}\right)=\frac{1}{1+e^{-y_{-} n e t_{k}}}
\end{aligned}
$$

g. Step 6 (steps 6-7 is a phase 2)

Calculate the factor $\alpha$ based on the error output unit in each unit of output $\mathrm{y}_{\mathrm{k}}(\mathrm{k}=1$, $2, \ldots, \mathrm{m})$.

$\delta_{k}=\left(t_{k}-y_{k}\right) f^{\prime}\left(y_{-} n e t_{k}\right)=\left(t_{k}-y_{k}\right) y_{k}\left(1-y_{k}\right)$

Which $t_{k}=$ output target

$\delta_{\mathrm{k}}$ is a unit of error that will be used in a weight change of the layer below it. Calculate the change in weight $\mathrm{w}_{\mathrm{kj}}$ at learning rate $\alpha$

$$
\Delta w_{k j}=a \delta_{k} z_{j}, k=1,2, \ldots \ldots, m ; j=0,1, \ldots . . p
$$

\section{h. Step 7}

Calculate the factor $\alpha$ hidden units based on the error at each hidden unit $z_{j}(j=1,2, \ldots$, p).

$$
\delta_{-} n e t_{j}=\sum_{k=1}^{m} \delta_{k} w_{k j}
$$

Factor $\delta$ hidden units

$$
\delta_{j}=\delta_{-} n e t_{j} f^{\prime}\left(z_{-} n e t_{j}\right)=\delta_{-} n e t_{j} z_{j}\left(1-z_{j}\right)
$$

Calculate the weight change rate $\mathrm{v}_{\mathrm{ji}}$.

$$
\Delta v_{j i}=a \delta_{j} x_{i t}, j=1,2, \ldots \ldots, p ; i=1,2, \ldots \ldots, n
$$

i. Step 8 (phase 3)

Calculate the weights of all the changes. Changes in weight of the line leading to the output unit.

$w_{k j}($ new $)=w_{k j}($ old $)+\Delta w_{k j} \cdot(k=1,2, \ldots ., m: j=0,1, \ldots, p)$.

Changes in weight of the line leading to the hidden units

$v_{j i}($ new $)=v_{j i}($ old $)+\Delta v_{j i} \cdot(j=1,2, \ldots ., p: i=0,1, \ldots, n)$.

The parameter $\alpha$ is the rate that determines the speed of understanding iteration. Value of $\alpha$ lies between 0 and 1 ( 0 $\leq \alpha \leq 1)$. The larger the $\alpha$ the price, the fewer iterations are used. But if the price $\alpha$ is too large, it will damage the pattern is correct so that understanding to be slow. One training cycle that involves all patterns are called epoch

\section{SELECTING AND USING THE OPTIMUM NETWORK STRUCTURE}

Selecting and Using the Optimum Network Structure Network that is built will be assessed the accuracy of his predictions. Valuation rules used is the value of Percentage Error (PE), Mean Absolute Percentage Error (MAPE) and Mean Square Error (MSE). MAPE approach used to assess the performance of trained networks because MAPE know exactly signify the 
relationship between forecast data with actual data through a percentage of the actual data and indicators of positive or negative on error (error) is ignored. Model accuracy is measured in relative terms using the PE and be seen also from its MSE value. PE values, MAPE and MSE obtained from the equation below

PE

$P E=\frac{\left(y_{t}-\hat{y}_{t}\right)}{y_{t}} \times 100 \%$

Which

$\mathrm{y}_{\mathrm{t}}=$ actual value at time $\mathrm{t}$. $\mathrm{y}_{\mathrm{t}}=$ forecast value at time $\mathrm{t}$.

MAPE

MAPE $=\sum_{1}^{n} \frac{|P E|}{n}$

with,

$\mathrm{n}=$ number forecast

$|\mathrm{PE}|=$ absolute $\mathrm{PE}$ values

MSE

$M S E=\frac{1}{n} \sum_{i=1}^{n} e_{i}^{2}=\frac{1}{n} \sum_{i=1}^{n}\left(y_{t}-\hat{y}_{t}\right)$

Which

$\mathrm{y}_{\mathrm{t}}=$ actual value at time $\mathrm{t}$.

$\mathrm{y}_{\mathrm{t}}=$ forecast value at time $\mathrm{t}$.

\section{FACTOR ARE AFFECTING CURRENCY EXCHANGE}

Variables that affect the monetary value of the rupiah against the U.S. dollar is the difference between Indonesia and the U.S. real income, the difference between Indonesia and the U.S. inflation, foreign interest rates and the U.S. Indonesia (Tri Wibowo, 2005).

\section{MySQL and PHP}

MySQL (My Structured Query Language) is one type of database server that is very famous. Popularity due to MySQL using SQL as a base to access its database. In addition, MySQL is Open Source (every person has the authority to access and use it for non-commercial use) on various platforms. MySQL RDBMS including types (Kadir, 2008).

In addition to installation and use of which is free of MySQL still has some advantages. As a fast data access and able to meet the needs of its users. However, MySQL does not have all the markers for a relational database, the MySQL developers to continue to make improvements each time so that later the current shortage of MySQL can be minimized.

PHP stands for Personal Home Page, is a scripting language that is bundled with HMTL, which runs on the server side. The majority of his orders come from C, Java and Pearl with some additional special functions of PHP. This language allows the 
makers of web applications HMTL pages present a dynamic and interactive to quickly and easily generated server.

PHP makes the application development process becomes easier as strengths, namely:

1. Script (program code) is integrated with an HTML file, so that developers can concentrate directly on the appearance of web documents.

2. No compiling and linking process.

3. Object-oriented (object oriented).

4. Syntax programming easy to learn, much like $\mathrm{C}$ and Perl.

5. Integration into a very wide range of database servers. Writing a web that connects to the database becomes very simple. Database supported by PHP: Oracle, Sybase, mSQL, MySQL, Solid, ODBC, PostgreSQL, etc

\section{COLLECTING DATA}

This phase aims to obtain data required in the processing of data to be carried out in accordance with the problems faced. Data collected are:

a. The rupiah against the U.S. dollar from January 2006 - December 2010 obtained from the website http://www.bi.go.id

b. Difference in Indonesia and U.S. real income obtained from their respective websites and http://www.budget.gov http://www.wikipedia.com

c. Difference in Indonesia and the U.S. inflation rate obtained from the respective websites and http://www.inflationdata.com http://www.bi.go.id

d. And foreign interest rates Indonesia America from January 2006 - November 2010 respectively obtained from the website http://www.global-rate.com and http://www.bi.go.id

The data used as input data is weekly. It is based on research conducted Zhang and Hu. They stated that if the use of monthly data, artificial neural networks in forecasting foreign exchange rates will not show an increase in performance when compared with linear methods. But if you use weekly data, neural network performance will be better than the linear method (Zhang and $\mathrm{Hu}, 1997)$.

\section{DATA PROCESSING}

In data processing forecasting divided in two ways, namely by including variables that affect exchange rates and without entering variables that affect exchange rates. Forecasting uses the help of software VB.Net.

Normalizing Data 
At this stage the data in the normalization of the range [0.1 to 0.9]. This data is normalized default by changing the range to $\left[\begin{array}{ll}0.1 & 0.9\end{array}\right]$ with the following equation.

$$
x_{i} \cdot=\frac{0,8 \times\left(x_{i}-\min x\right)+0,1}{\max x-\min x}
$$

$\mathrm{xi}=$ the $\mathrm{i}^{\text {th }}$ data

$\min x=$ minimum data from period 1 to 261

$\mathrm{x} \max =$ maximum data from period 1 to 261

xi '= normalized value

\section{DESIGNING NEURAL NETWORK} STRUCTURE

Structure of artificial neural networks are used in forecasting exchange rates are: 1. The number of layers used is 3 layer 1 input layer, one hidden layer and an output layer.

2. Number of hidden layers used is 1 .

3. The number of neurons in the layer in 1 , 2, 3 and 4 is a method of trial and error to see the smallest error value, while for forecasting without inserting the variables that influence wear only one neuron.

4. Activation function used is the binary sigmoid.

After all the artificial neural network structure is formed, continue to forecast exchange rates. Used for forecasting VB.Net programming language. Phase weighting to initially use a small random number, so natinya artificial neural network system will repair itself how much actual weight for each - each of these variables during the training period. The following figure artificial neural network structure. Figure 15 is all of the artificial neural network structure used in this paper.

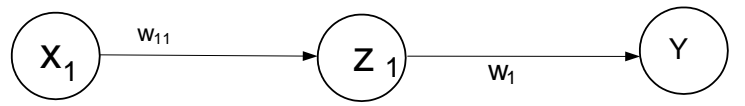

Figure 1. Structure Incorporating Neural Networks without Affecting Variables

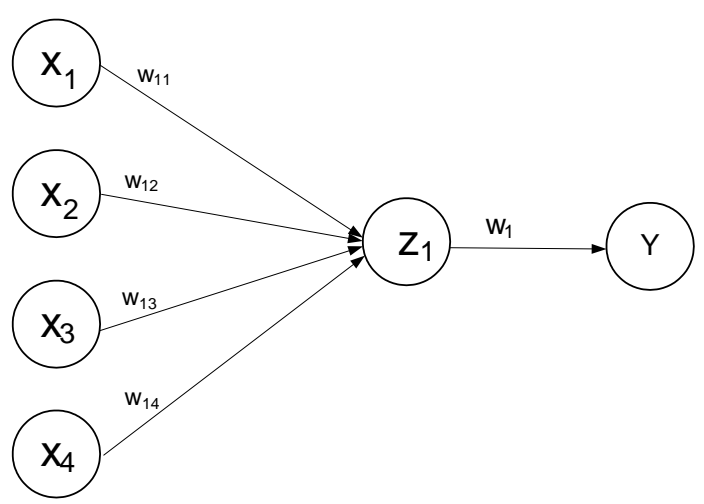

Figure 2. Structure of Neural Networks with Variable Affecting Insert and 1 Hidden Neurons 


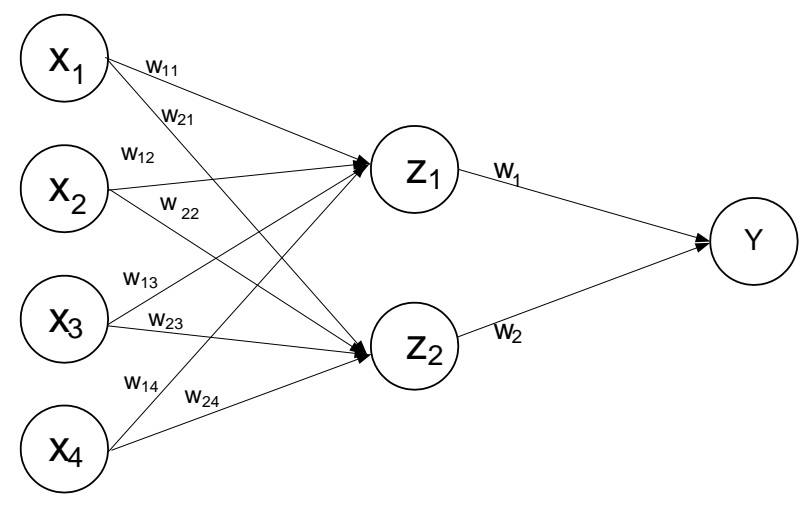

Figure 3. Structure of Neural Networks with Variable Affecting Insert and 2 Hidden Neurons

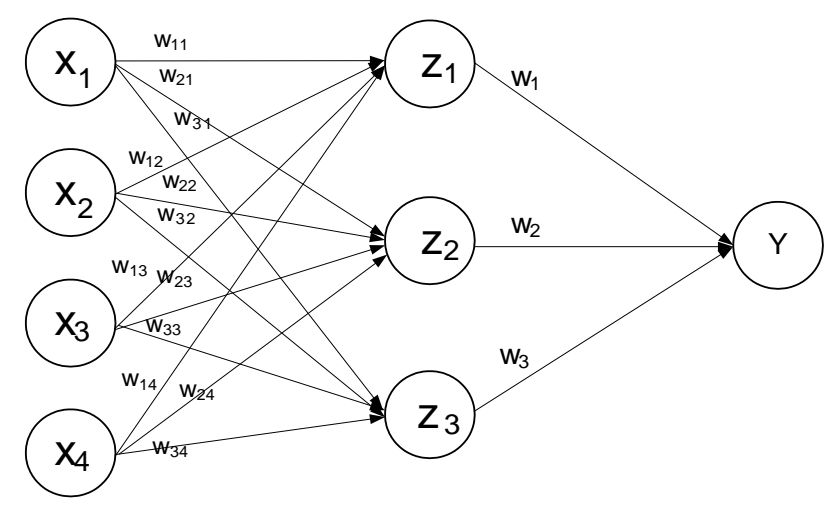

Figure 4. Structure of Neural Networks with Variable Affecting Insert and 3 Hidden Neurons

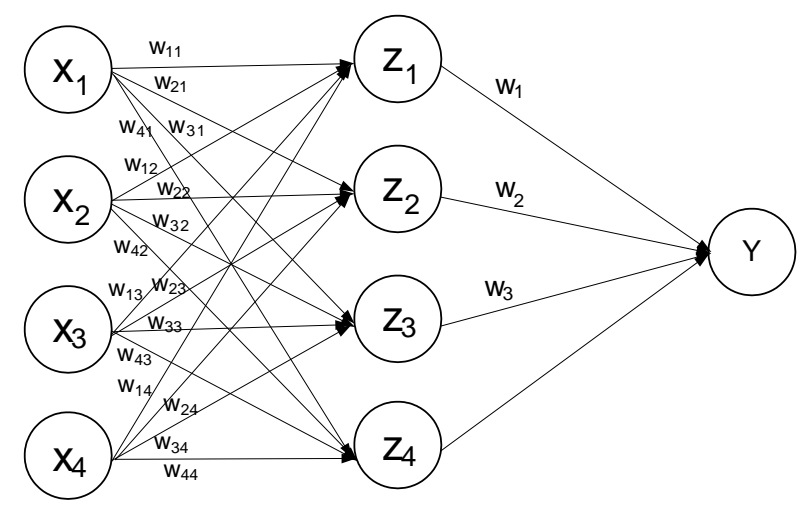

Figure 5. Structure of Neural Networks with Variable Affecting Insert and 4 Hidden Neurons

FORECASTING RUPIAH EXCHANGE RATES AGAINST THE U.S. DOLLAR WITH NEURAL NETWORKS WITHOUT ENTERING VARIABLES THAT AFFECT EXCHANGE RATES

This stage begins with determining the value of ratings to learn, and to the data in the form of an ever-changing data should be used in rating the small study, so that the results of forecasting is not too distorted. And in this research study used a 0.01 rating value for forecasting exchange rates. Having established how the value of rating learning, neural networks are trained. Neural network training using $90 \%$ of the data that is week 1 through 235. After the data were trained, to do the testing phase as well as artificial neural networks predicted the rupiah against the U.S. without entering the variables that affect exchange rates, using the remaining $10 \%$ of the data that is weeks to 236 to 260 
to 24 pairs of data. The following is a graph of the test results of forecasting

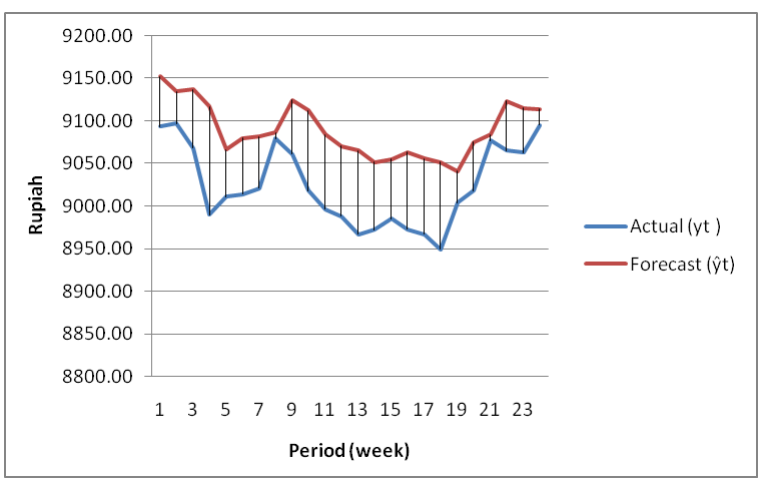

Figure 6. Comparison Graph of Actual Results Forecasting and Exchange without the inclusion of the Variables that Affect Exchange Rates

The following is the results of forecasting for 5 periods

Table 1. Currency Forecast without Inclusion Variable that Affect

\begin{tabular}{|c|c|}
\hline $\begin{array}{c}\text { Period } \\
\text { (week) }\end{array}$ & $\begin{array}{c}\text { Forecast } \\
\text { (Rupiah) }\end{array}$ \\
\hline 1 & 9095,00 \\
\hline 2 & 9147,20 \\
\hline 3 & 9172,43 \\
\hline 4 & 9190,45 \\
\hline 5 & 9203,55 \\
\hline
\end{tabular}

FORECASTING RUPIAH EXCHANGE RATES AGAINST THE U.S. DOLLAR WITH NEURAL NETWORKS AND ENTERING VARIABLES THAT AFFECT EXCHANGE RATES

This Forecasting method is not much different from the forecast without entering the variables that influence, the difference is that we include variables that affect exchange rates and we should try as much as what the neurons that will be used in the hidden layer. Then we set the variable as follows:

a. Exchange rate $=\mathrm{x} 1$

b. Difference in inflation $=x 2$

c. Difference in interest rates $=x 3$

d. Difference in Gross National Product = $\mathrm{x} 4$

Continue with the training, but in this training must be tried by the number of neurons in the 1 layer of neurons, 2 neurons, 3 neurons and 4 neurons.

The following chart shows the comparison of forecasting results and the actual value of the currency exchange rate 1 neuron in hidden layers.

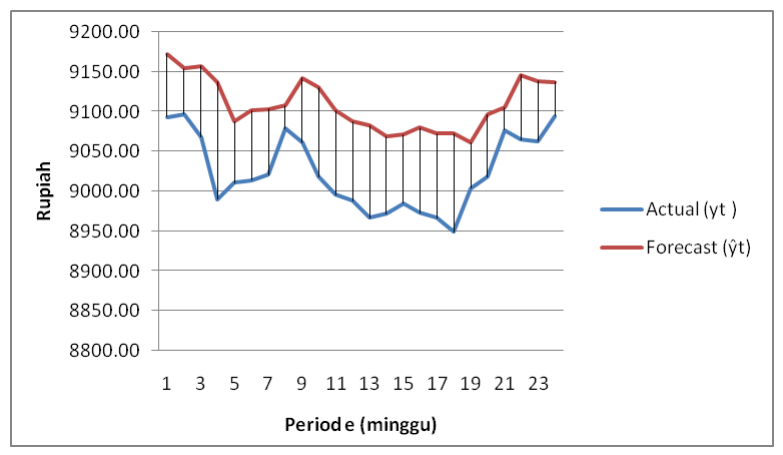

Figure 7. Comparison of forecasting results and the actual value of the currency exchange rate 1 neuron in hidden layers.

The following is the results of forecasting for 5 periods 1 neuron in hidden layers. 
Table 2. Currency Forecast Inclusion Variable that Affect 1 neuron in hidden layers

\begin{tabular}{|c|c|}
\hline $\begin{array}{c}\text { Period } \\
\text { (week) }\end{array}$ & $\begin{array}{c}\text { Forecast } \\
\text { (Rupiah) }\end{array}$ \\
\hline 1 & 9159,12 \\
\hline 2 & 9130,88 \\
\hline 3 & 9179,07 \\
\hline 4 & 9204,44 \\
\hline 5 & 9229,44 \\
\hline
\end{tabular}

The following chart shows the comparison of forecasting results and the actual value of the currency exchange rate 2 neurons in hidden layers.

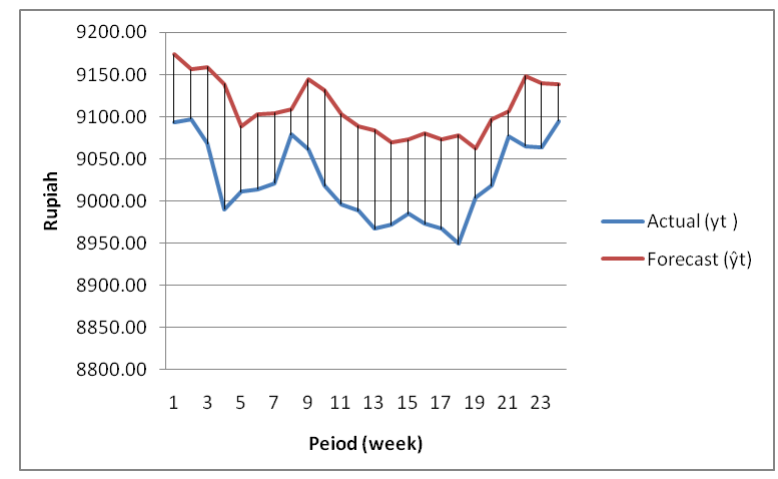

Figure 7. Comparison of forecasting results and the actual value of the currency exchange rate 2 neuron in hidden layers.

The following is the results of forecasting for 5 periods 2 neuron in hidden layers.
Table 3. Currency Forecast Inclusion Variable that Affect 2 neuron in hidden layers

\begin{tabular}{|c|c|}
\hline $\begin{array}{c}\text { Period } \\
\text { (week) }\end{array}$ & $\begin{array}{c}\text { Forecast } \\
\text { (Rupiah) }\end{array}$ \\
\hline 1 & 9135,94 \\
\hline 2 & 9185,89 \\
\hline 3 & 9170,61 \\
\hline 4 & 9208,05 \\
\hline 5 & 9233,14 \\
\hline
\end{tabular}

The following chart shows the comparison of forecasting results and the actual value of the currency exchange rate 3 neurons in hidden layers.

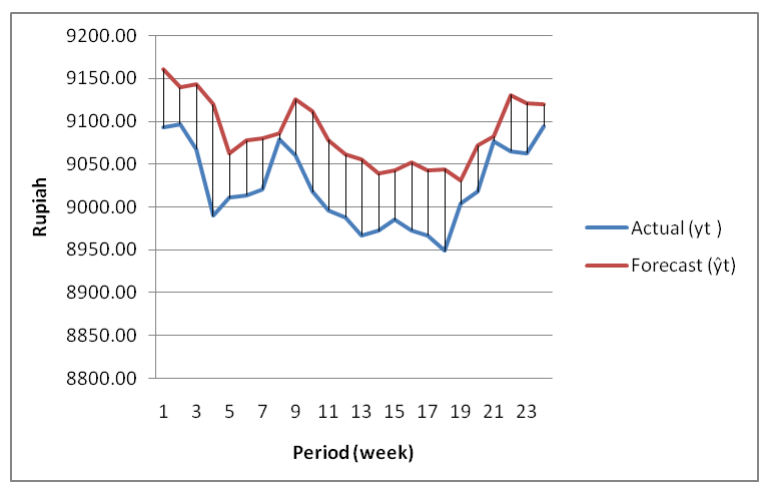

Figure 8. Comparison of forecasting results and the actual value of the currency exchange rate 3 neuron in hidden layers.

The following is the results of forecasting for 5 periods 3 neuron in hidden layers. 
Table 4. Currency Forecast Inclusion Variable that Affect 3 neuron in hidden layers

\begin{tabular}{|c|c|}
\hline $\begin{array}{c}\text { Period } \\
\text { (week) }\end{array}$ & $\begin{array}{c}\text { Forecast } \\
\text { (Rupiah) }\end{array}$ \\
\hline 1 & 9116,44 \\
\hline 2 & 9157,83 \\
\hline 3 & 9189,57 \\
\hline 4 & 9214,88 \\
\hline 5 & 9211,47 \\
\hline
\end{tabular}

The following chart shows the comparison of forecasting results and the actual value of the currency exchange rate 4 neurons in hidden layers.

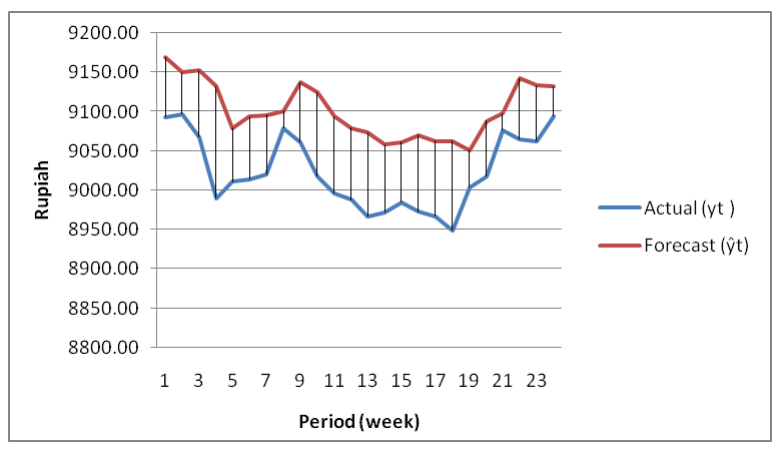

Figure 9. Comparison of forecasting results and the actual value of the currency exchange rate 3 neuron in hidden layers.

The following is the results of forecasting for 5 periods 4 neuron in hidden layers.

Table 5. Currency Forecast Inclusion Variable that Affect 3 neuron in hidden layers

\begin{tabular}{|c|c|}
\hline $\begin{array}{c}\text { Period } \\
\text { (week) }\end{array}$ & $\begin{array}{c}\text { Forecast } \\
\text { (Rupiah) }\end{array}$ \\
\hline 1 & 9128,72 \\
\hline 2 & 9175,99 \\
\hline 3 & 9211,89 \\
\hline 4 & 9236,63 \\
\hline 5 & 9253,26 \\
\hline
\end{tabular}

COMPARING PERFORMANCE

MODELS WITH NEURAL NETWORKS WITHOUT ENTERING VARIABLES THAT AFFECT EXCHANGE RATES

At this stage to compare the forecasting performance of the rupiah against the U.S. dollar and enter without entering variables that influence. Valuation rules used is the value of Percentage Error (PE), Mean Absolute Percentage Error (MAPE) and Mean Square Error (MSE)

VALUE FORECASTING ARTIFICIAL WITH AND

\section{(1)} g

.


Table 6. Comparison of forecasting results

\begin{tabular}{|l|c|c|}
\hline \multicolumn{1}{|c|}{ Metode } & MAPE & MSE \\
\hline $\begin{array}{l}\text { Without Inclusion Variables } \\
\text { Affecting }\end{array}$ & 0,72569 & 5122,55 \\
\hline $\begin{array}{l}\text { Inclusion Variables Affecting } \\
\text { (1 neuron in hidden layer) }\end{array}$ & 0,944 & 8018,52 \\
\hline $\begin{array}{l}\text { Inclusion Variables Affecting } \\
(2 \text { neuron } \text { n hidden layer })\end{array}$ & 0,96522 & 8360,88 \\
\hline $\begin{array}{l}\text { Inclusion Variables Affecting } \\
(3 \text { neuron n hidden layer })\end{array}$ & 0,69581 & 4686,42 \\
\hline $\begin{array}{l}\text { Inclusion Variables Affecting } \\
\text { (4 neuron n hidden layer })\end{array}$ & 0,86355 & 6819,79 \\
\hline
\end{tabular}

Designing a Web Page to Display Output From Calculation Designing web pages using PHP software. This web page displays the results of forecasting exchange rates has been done as well as provide access to people in order to attempt to use artificial neural network forecasting program, as well as giving people access to download the application.

\section{CONCLUSIONS AND}

\section{RECOMMENDATIONS}

MAPE approach used to assess the performance of trained networks because MAPE know exactly signify the relationship between forecast data with actual data through a percentage of the actual data and indicators of positive or negative on error (error) is ignored. Model accuracy is measured in relative terms using the PE and be seen also from its MSE value.
For the test data obtained Mape smallest value of $0.69581 \%$. This illustrates that the network with 3 neurons in a sprinkling can study the data well based on 24 data patterns are used. This value is much smaller than the value Mape from another network, so the network can see this is a significant relationship between variables. It is already quite good because it is usually small Mape value of $10 \%$ could be acceptable. This means that network all networks is acceptable but it is best to network with 3 neurons in the network.

Performance comparison between artificial neural networks by incorporating artificial neural network variables and by including variables that influence can be compared to the value of PE and its MSE. From these results can be analyzed that turned out, despite entering the variables that influence, does not guarantee that the forecasts made will be better than without entering the variables that influence. Can be seen from the results of the assessment rules are used that neural networks are designed without entering a variable that affects better than some of the artificial neural network that uses variables that influence.

From the test results can be (table 8.) Can be seen that the difference in the value of forecasting results and the actual data is not 
too large. It is proved that artificial neural networks that use variables that affect and 3 neurons in the can to forecast the exchange rate well. So the artificial neural network forecasting results using variables that affect and 3 neurons can be said to show the results of forecasting for 5 periods ahead. The use of 5 periods ahead even this is useful for predicting the highest and lowest value of the currency exchange rate fluctuations is.

As for recommendation that can be given is for further study, is order to be able to forecast exchange rates not only between the Rupiah and U.S. dollar, but also the currency of other countries such as the ASEAN countries and other developed countries. And is also expected Forecasting with artificial neural network method is used for the determination of the production floor as well as the determination of the amount of inventory and warehouse area. 


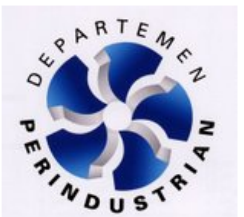

Home Download Aplikasi

\section{Hasil Peramalan}

\begin{tabular}{|l|l|}
\hline Periode (Minggu) & Nilai Ramalan (Rupiah) \\
\hline 1 & 9116.44 \\
\hline 2 & 9157.83 \\
\hline 3 & 9189.57 \\
\hline 4 & 9214.88 \\
\hline 5 & 9211.47 \\
\hline
\end{tabular}

Figure 10. Homepage of result forecasting

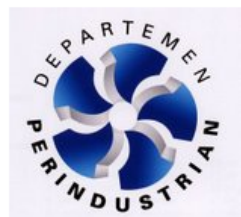

Home Download Aplikasi

\section{Silahkan Coba Dan Download Aplikasinya}

$\begin{array}{lc}\text { Nama Aplikasi } & \text { Pilihan } \\ \text { Peramalan Dengan Menggunakan Jaringan Syaraf Tiruan } 1 \text { Variabel } & \text { Coba | Download } \\ \text { Peramalan Dengan Menggunakan Jaringan Syaraf Tiruan } 4 \text { Variabel } & \text { Coba | Download }\end{array}$

Figure 11. Page to try and download the software

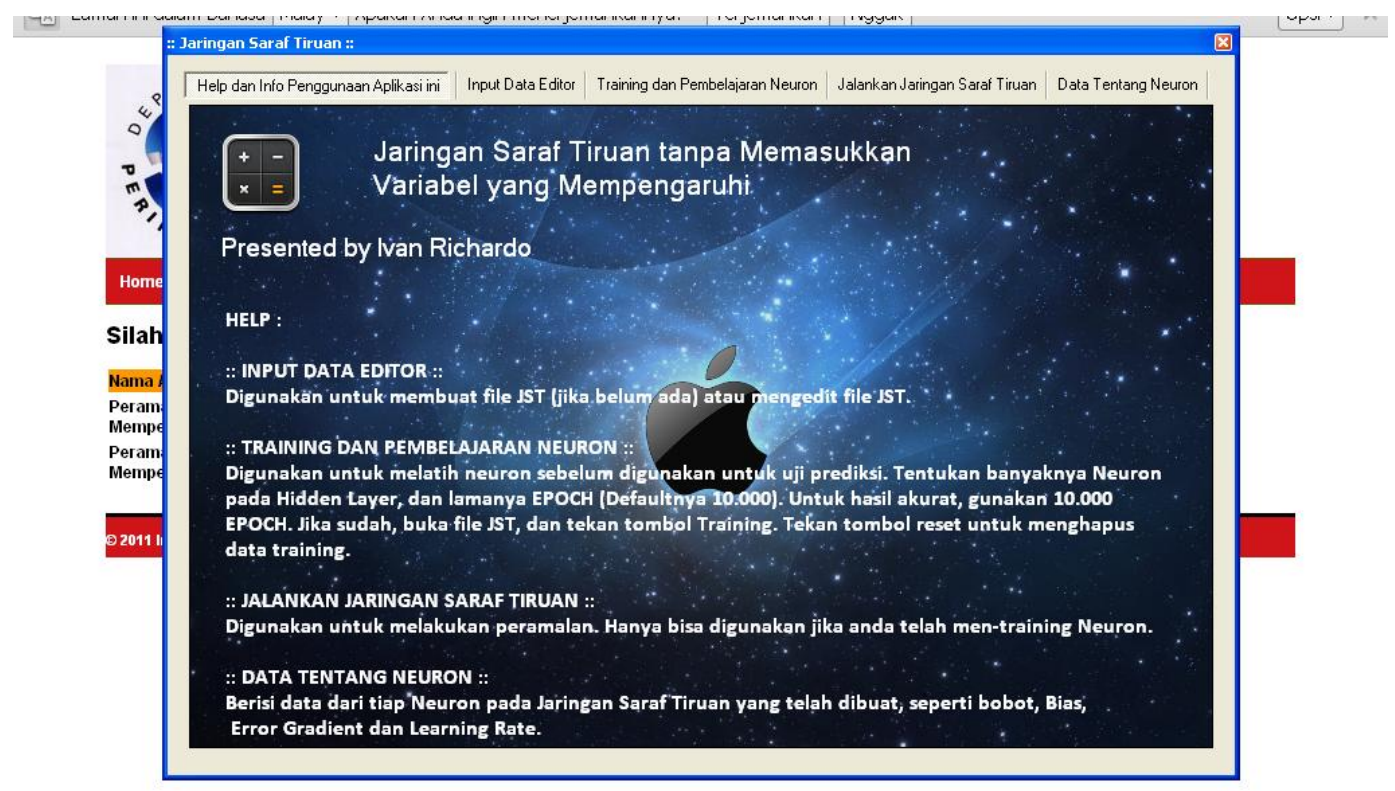

Figure 12. User Interface of Forecasting 


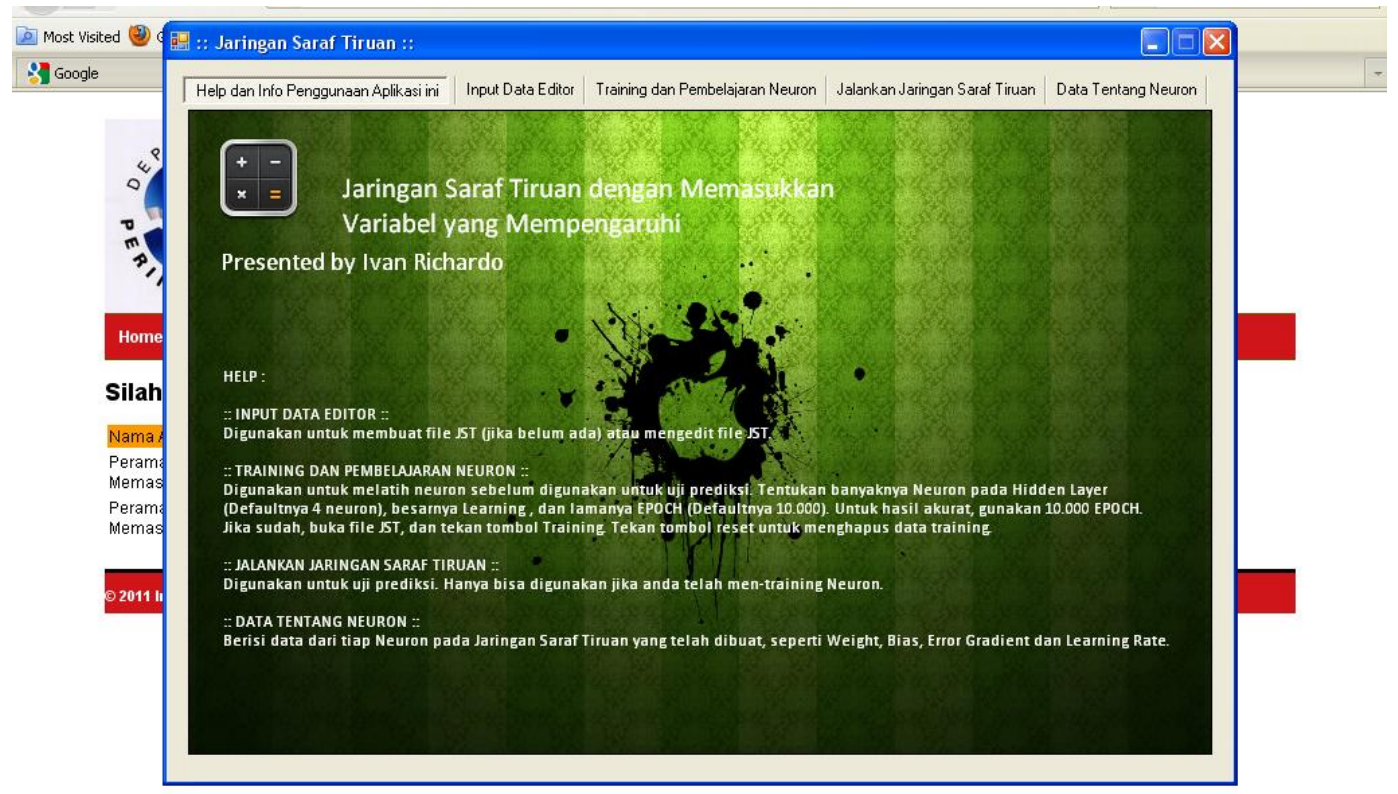

Figure 12. User Interface of Forecasting

\section{REFERENCES}

Box, G. E. P., Jenkins, G. M. (1994). Forecasting and Control. New Jersey: Prentice Hall.

Dadashzhadeh, Muhammad. (2010). Microcomputer Based-Decision Support for Facilities Planning. International Journal of Green Computing.

Dorsey, Robert E. and John D Johnson. (2010). Microcomputer System and management. International Journal of Green Computing.

Kadir, Abdul. (2001). Dynamic Web Programming Basics Using PHP. Yogyakarta: Andi Offset.

Kemal Sekarwati Ade, Herman Agustiawan. (2005). Stock Price Prediction Using Neural
Networks. Master's Thesis. Gunadarma University, Indonesia.

Makridakis, Spyros., Syeven C. Wheelwright., And Victor E. McGee. (1999). Forecasting Methods and Applications. Jakarta: Binarupa script.

Muhammad, Mahater. (2010). Comparison of Backpropagation Artificial Neural Network and Method of Arima (Box-Jenkins) As a Method of Forecasting Currency Rupiah against the U.S. dollar. University of North Sumatra, Indonesia. Mulyono, Sri, (2000), Forecasting Stock Prices and Exchange Rates: Box-Jenkins Techniques. Economics and Finance Indonesia, Vol. XLVIII No.2

Office of Management and Budget. (2011). Historical Budget og U.S Government. 
Washington, DC. : U.S Government Printing Office

Sexton, Randall S. Beyond Backpropagation: using simulated annealing for training neural network. International Journal of green Computing.

Siang, Jong jack. (2005). Artificial Neural Networks Using Matlab and pemogramannya. Yogyakarta: Andi Offset. Subiyanto. (2000). Application of Artificial Neural Networks as an Alternative Method of
Short-Term Load Forecast. Accessed on December 10, $2010 . \quad$ From http://www.elektroindonesia.com/elektro/ener 29.html-42k-

Wibowo, Tri and Amir. (2005). Factors Affecting Exchange Rate Euro. Journal of economic studies and financial.

Zhang, G., Pattuwo, B.E., and Hu, M.Y. (1997). Forecasting with Artificial Neural Networks. The State of the Art: Elsevier International Journal of Forecasting 